\title{
Late systemic desaturation after total cavopulmonary shunt operations
}

\author{
O Stümper, J G C Wright, M Sadiq, J V De Giovanni
}

\begin{abstract}
Objectives-To assess the medium-term results of total cavopulmonary shunt operations in children with left atrial isomerism, interrupted inferior vena cava, and complex congenital heart defects.

Background-Creation of a total cavopulmonary shunt provides very good interim palliation for children with interrupted inferior vena cava and complex congenital heart disease; however, longer term results after this operation have not been reported.
\end{abstract}

Methods-Detailed follow up of six children who underwent creation of a total cavopulmonary shunt at a tertiary referral centre.

Results-There were no early or late deaths. Oxygen saturations at discharge ranged from $89 \%$ to $92 \%$ (mean $90 \%$ ). At last follow up (mean 4.7 years) saturations at rest ranged from $73 \%$ to $81 \%$ (mean 77\%) $(P<0.05)$. All patients underwent exercise stress testing. At peak exercise oxygen saturations ranged from $62 \%$ to $87 \%$ (mean $71.5 \%$ ) and during recovery from $68 \%$ to $85 \%$ (mean $78 \%$ ). Cardiac catheterisation was performed in five patients with saturations of less than $80 \%$ at rest or peak exercise. No patient had pulmonary arteriovenous fistula. Systemic venous to hepatic venous collaterals were documented in four patients. These were localised below the diaphragm in three and above the diaphragm in one patient. The collateral vessel was successfully embolised in three of these patients, with a rise in resting oxygen saturations from 6 to $10 \%$ (mean 7\%).

Conclusions-The development of systemic venous to hepatic venous collaterals is a common complication in patients who undergo a total cavopulmonary shunt operation. This can lead to significant desaturation at rest and during exercise. Detailed angiographic studies of the infradiaphragmatic systemic veins is required for diagnosis. Transcatheter embolisation of such vessels gives good relief.

(Br Heart $\mathcal{F} 1995 ; 74: 282-286)$

Keywords: total cavopulmonary shunt; systemic desaturation; left atrial isomerism
Left atrial isomerism is commonly associated with complex cyanotic congenital heart disease and either azygos or hemiazygos continuation of an interrupted inferior vena cava. Most patients with left atrial isomerism are not suitable for a biventricular surgical repair. The creation of a total cavopulmonary shunt between the superior vena cava and the pulmonary artery ${ }^{2}$ offers good palliation in these patients. All the systemic venous blood is redirected to the pulmonary arteries after this operation, whereas hepatic venous blood enters the atrial chambers. Thus, there remains a small residual right to left shunt which leads to mild desaturation with oxygen saturations of about $90 \%$. The early results after this operation are very good, however, systematic long-term results have not been reported.

Because the hepatic venous return in these patients is not directed to the lungs, the portal venous pressure is lower than the systemic venous pressure. Thus, there would seem to be a risk for the late development of collaterals and fistulous communications between the systemic venous and hepatic venous system leading to progressive systemic desaturation.

All patients who underwent a total cavopulmonary shunt in the presence of either azygos or hemiazygos continuation of an interrupted inferior vena cava at the Birmingham Children's Hospital were evaluated to assess the long-term results of this operation.

\section{Patients and methods}

PATIENTS

Between March 1984 and March 1991 nine patients with left atrial isomerism, azygos or hemiazygos continuation of an interrupted inferior vena cava, and complex congenital heart disease who were unsuitable for a biventricular repair underwent operation. A total cavopulmonary shunt was created in seven children with no early mortality. One of these patients experienced marked early postoperative cyanosis and low cardiac output failure. The cardiac catheter at that time documented a large collateral vessel between the systemic veins and the left atrium. The patient subsequently underwent an atrial baffle procedure connecting both the collateral and the hepatic venous blood to the pulmonary artery (modified Fontan procedure). A further two patients underwent a combination of total 
cavopulmonary shunt and atrial baffle for redirection of the hepatic venous blood to the pulmonary arteries.

The study population of this report consists of the six patients who underwent isolated total cavopulmonary shunt (table 1).

\section{SURGERY}

One patient (no 1) underwent creation of bilateral bidirectional cavopulmonary shunts (resulting in a total cavopulmonary shunt) at 10 years of age via bilateral lateral thoracotomies. The remaining five patients underwent creation of a total cavopulmonary shunt using cardiopulmonary bypass. In three patients the shunt was created on the right side, in one with bilateral superior venae cavas on both the right and the left side and in one with a single left superior vena cava and hemiazygos continuation on the left side. Concomitant pulmonary artery reconstruction was performed in three patients. The main pulmonary artery was trans-sected and oversewn at the time of operation in four of the five patients with subpulmonary stenosis and anterograde pulmonary blood flow. The main pulmonary artery was left in continuity with the central pulmonary artery system in only one patient (no 1), thus allowing for competitive pulmonary blood flow after the procedure. There were no perioperative deaths.

\section{FOLLOW UP}

The follow up interval ranged from three to 10 years (mean 4.7 years). There were no late deaths. All patients had routine follow up which included clinical examination, pulse oxymetry, electrocardiogram, and cardiac ultrasound examination. Exercise stress tests were performed using a modified Bruce protocol at last follow up. Heart rate and pulse oxymetry were recorded continuously.

\section{CARDIAC CATHETERISATION}

Indications for subsequent cardiac catheterisation and angiography were based on the documentation of significant desaturationthat is, saturations of more than $10 \%$ less than saturations recorded at the time of hospital discharge, at rest or peak exercise. Cardiac catheter studies were performed under general anaesthesia. Positive end expiratory pressure ventilation was used in two patients with mean systemic venous pressures of less than $12 \mathrm{~mm} \mathrm{Hg}$ to increase systemic venous pressure to a higher level. Studies were directed to exclude any pressure gradients between the systemic venous system and the branch pulmonary arteries. Angiograms were performed using standard views and aimed to delineate the pattern of systemic venous return, the site of the anastomosis, and the pulmonary vasculature. Pulmonary arteriovenous fistulae were judged to be absent on demonstration of a normal pulmonary artery capillary bed and absence of early pulmonary venous opacification during right and left pulmonary angiography. Left heart function was assessed during the laevophase of pulmonary artery injection. In addition, all patients underwent an angiogram of the iliac veins and the abdominal inferior vena cava with follow through to the azygos or hemiazygos system and the superior vena cava. This was in an attempt to exclude any infradiaphragmatic collateral vessels to the portal or hepatic venous system.

\section{EMBOLISATION TECHNIQUES}

Collaterals between the systemic and hepatic venous circulation were embolised using either detachable silicone balloons or stainless steel coils (both E. Merck Ltd, Winchester Road, Four Marks, Alton, United Kingdom). The detachable balloons were placed using the appropriate delivery catheters and filled with isotonic contrast material. Stainless steel coils were delivered using a 6 French end-hole catheter placed at the appropriate site. Routine antibiotic prophylaxis was given for $48 \mathrm{~h}$ after the procedure.

\section{Results}

There were no early or late deaths.

Arterial oxygen saturations at the time of hospital discharge ranged from 89 to $92 \%$, with a mean of $90 \%$. At last follow up oxygen saturations at rest were documented to range from 73 to $81 \%$ (mean $77 \%$ ) $(P<0.05$, Students $t$ test). The decrease in oxygen saturations at last follow up compared to those at hospital discharge ranged from 10 to $16 \%$ (mean 13\%).

During exercise testing oxygen saturations decreased to $62-87 \%$ (mean $71.5 \%$ ) at peak excercise and $68-85 \%$ (mean $78 \%$ ) during recovery (table 2 ). In one patient (no 2) there was an increase in oxygen saturations at peak exercise and during recovery $(87 \%$ and $85 \%$ respectively) compared with saturations at rest $(81 \%)$. This finding was judged to reflect a ventilation perfusion mismatch, and the

Table 1 Patient data

\begin{tabular}{lllllll}
\hline $\begin{array}{l}\text { Patient } \\
\text { no }\end{array}$ & Diagnosis & SVC & IVC & $\begin{array}{l}\text { Date of } \\
\text { operation }\end{array}$ & $\begin{array}{l}\text { Age at } \\
\text { operation } \\
\text { (years) }\end{array}$ & Procedure \\
\hline 1 & cAVSD,TGA,sPS & R/L & Azygos & March 1984 & $9 \cdot 3$ & Bilateral CP shunt \\
2 & cAVSD,DORV,sPS & R & Azygos & April 1990 & $2 \cdot 2$ & Right CP shunt \\
3 & cAVSD,TGA,PA,PDA & R & Azygos & October 1990 & $2 \cdot 3$ & Right CP shunt, PA reconstruction \\
4 & cAVSD,DORV,TGA,sPS & R/L & Azygos & January 1991 & $1 \cdot 3$ & Bilateral CP shunt, PA reconstruction \\
5 & cAVSD,DORV,SPS,PDA & R & Azygos & March 1991 & $1 \cdot 9$ & Right CP shunt \\
6 & cAVSD,DORV,TGS,sPS & L & Hemiazygos & March 1991 & $7 \cdot 0$ & Left CP shunt, PA reconstruction \\
\hline
\end{tabular}

cAVSD, complete atrioventricular septal defect; CP, cavopulmonary; DORV, double outlet right ventricle; IVC, continuation of inferior vena cava; L, left; PA, pulmonary atresia; R, right; sPS, subpulmonary stenosis; SVC, superior vena cava; TGA, inferior vena cava; L, left; PA, pulmonary atresia; R, right; sPS,
transposition of the great arteries; PDA, patient ductus arteriosus. 
Table 2 Follow up results

\begin{tabular}{|c|c|c|c|c|c|c|c|c|}
\hline \multirow{2}{*}{$\begin{array}{l}\text { Patient } \\
\text { no }\end{array}$} & \multirow{2}{*}{$\begin{array}{l}\text { Postoperative } \\
\text { follow up } \\
\text { interval } \\
\text { (years) }\end{array}$} & \multirow{2}{*}{$\begin{array}{l}\text { Exercise } \\
\text { test } \\
\text { (min) }\end{array}$} & \multicolumn{3}{|c|}{ Saturations (\%) } & \multirow{2}{*}{$\begin{array}{l}\text { Catheterisation } \\
\text { findings }\end{array}$} & \multirow[b]{2}{*}{ Occlusion technique } & \multirow{2}{*}{$\begin{array}{l}\text { Post- } \\
\text { procedure } \\
\text { saturation } \\
\text { (at rest) } \\
(\%)\end{array}$} \\
\hline & & & Rest & Peal & Recovery & & & \\
\hline $\begin{array}{l}1 \\
2 \\
3\end{array}$ & $\begin{array}{c}10 \\
4 \cdot 2 \\
3 \cdot 8\end{array}$ & $\begin{array}{l}5 \\
6 \cdot 5 \\
9\end{array}$ & $\begin{array}{l}76 \\
81 \\
80\end{array}$ & $\begin{array}{l}65 \\
87 \\
73\end{array}$ & $\begin{array}{l}68 \\
85 \\
85\end{array}$ & $\begin{array}{l}\text { Multiple small fistulae } \\
\text { Infradiaphragmatic fistula }\end{array}$ & $\begin{array}{l}\text { Failed } \\
\frac{-}{0.5 \mathrm{~cm}^{3} \text { detachable }}\end{array}$ & 86 \\
\hline 4 & $3 \cdot 6$ & 6 & 78 & 72 & 74 & Infradiaphragmatic fistula & $\begin{array}{l}1.0 \mathrm{~cm}^{3} \text { detachable } \\
\text { balloon }\end{array}$ & 88 \\
\hline $\begin{array}{l}5 \\
6\end{array}$ & $\begin{array}{l}3 \cdot 5 \\
3 \cdot 2\end{array}$ & $\begin{array}{l}8 \\
5\end{array}$ & $\begin{array}{l}74 \\
73\end{array}$ & $\begin{array}{l}70 \\
62\end{array}$ & $\begin{array}{l}80 \\
78\end{array}$ & $\begin{array}{l}\text { No fistulae } \\
\text { Supradiaphragmatic fistula }\end{array}$ & $\overline{\text { Three coils }}$ & 79 \\
\hline
\end{tabular}

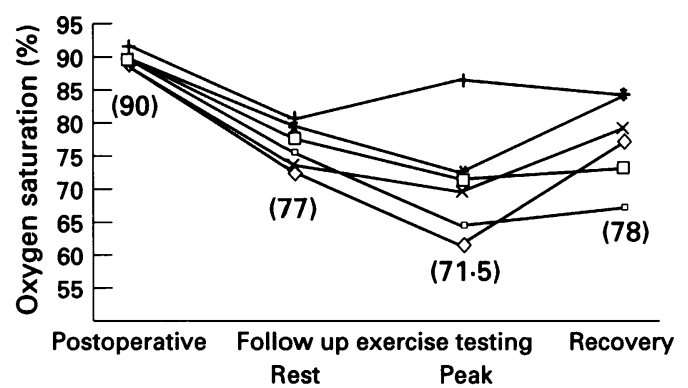

Figure 1 Changes in oxygen saturations after operation to last follow up and during exercise testing. Mean values are given in parentheses

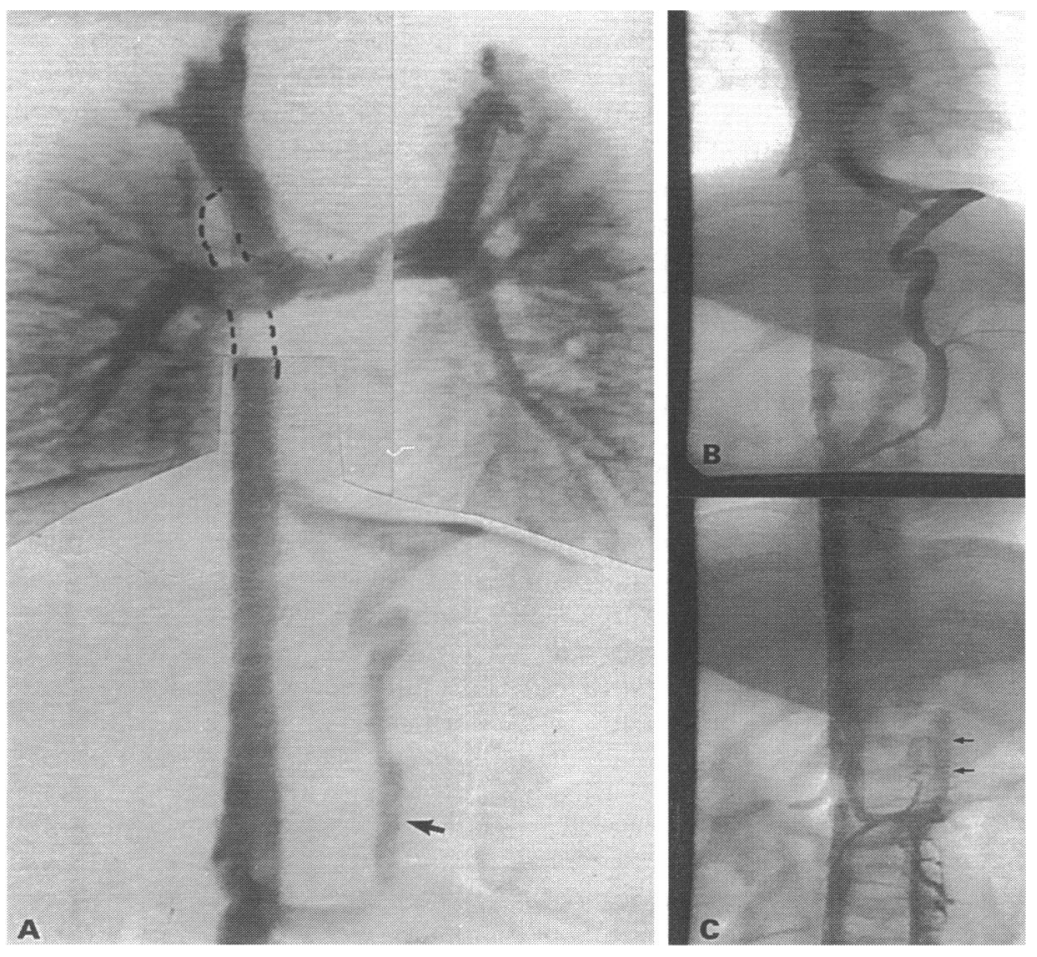

Figure 2 Composite of angiocardiograms of patient 4. (A) Injections into the right and lefi superior caval veins document a good sized pulmonary artery system with adequate capillary filling. There is no evidence of early pulmonary venous filling, thus excluding pulmonary arteriovenous fistulae. Injection into the azygos vein shows good run off to the right sided superior vena cava (dotted lines) and evidence of a large collateral vessel (arrow) draining into the hepatic venous system at the level of the diaphragm. (B) Selective injection into the infradiaphragmatic collateral vessel. (C) Complete occlusion of this vessel was achieved by embolisation with a detachable balloon (arrows). patient was not catheterized. In the remaining five patients oxygen saturations decreased between $4 \%$ and $11 \%$ (mean $8 \%$ ) at peak exercise compared with saturations at rest. Two of these patients had persistently decreased saturations during the recovery period (nos 1 and 4) and the remaining three had a slight increase in oxygen saturations (mean (range) $5(5-6) \%$ ) compared with the values at rest (fig 1 ).

Cardiac catheterisation excluded obstructions of either the anastomotic site or within the pulmonary artery system in five patients. Mean withdrawal gradients were less than $1 \mathrm{~mm} \mathrm{Hg}$. Angiograms demonstrated the absence of pulmonary arteriovenous fistulae.

Collateral vessels communicating between the systemic and the hepatic venous system were documented on angiograms in four patients ( $67 \%$ of study population). All four patients were documented to have a decrease in oxygen saturations of more than $5 \%$ at peak exercise (as compared with resting values). In two patients (nos 3 and 4) large infradiaphragmatic collateral vessels were documented (fig 2). Selective injections suggested a significant right to left shunt. The vessel was successfully occluded in each patient using a detachable silicone balloon (fig 3). There was no significant rise in systemic venous pressure in either patient after embolisation. Oxygen saturations at rest $24 \mathrm{~h}$ after the procedure were increased by $6 \%$ and $10 \%$ respectively (80-86\% and $78-88 \%$ ).

In one patient (no 1) numerous small fistulous communications were documented between the azygos system and the hepatic venous system. Before the procedure this patient had oxygen saturations of $76 \%$ at rest. During catheterisation systemic saturations were $86 \%$ and systemic venous pressure was only $12 \mathrm{~mm} \mathrm{Hg}$. Systemic venous pressure could not be raised sufficiently with positive pressure ventilation. Thus, a large latex balloon catheter was inflated in the azygos vein near its junction with the superior vena cava, so as to raise venous pressure to $15 \mathrm{~mm} \mathrm{Hg}$, and to increase any potential collateral run off. Numerous small collateral vessels were documented on subsequent angiograms: however, none of these vessels could be entered selectively and the procedure was abandoned. One patient (no 6) was found to have a small communication between the innominate vein 
Figure 3 Digital subtraction angiograms of patient 3. (A) Exclusion of pulmonary arteriovenous fistulae. (B)

Documentation of an infradiaphragmatic collateral vessel. (C) Complete occlusion of this vessel using a detachable balloon (dotted line)

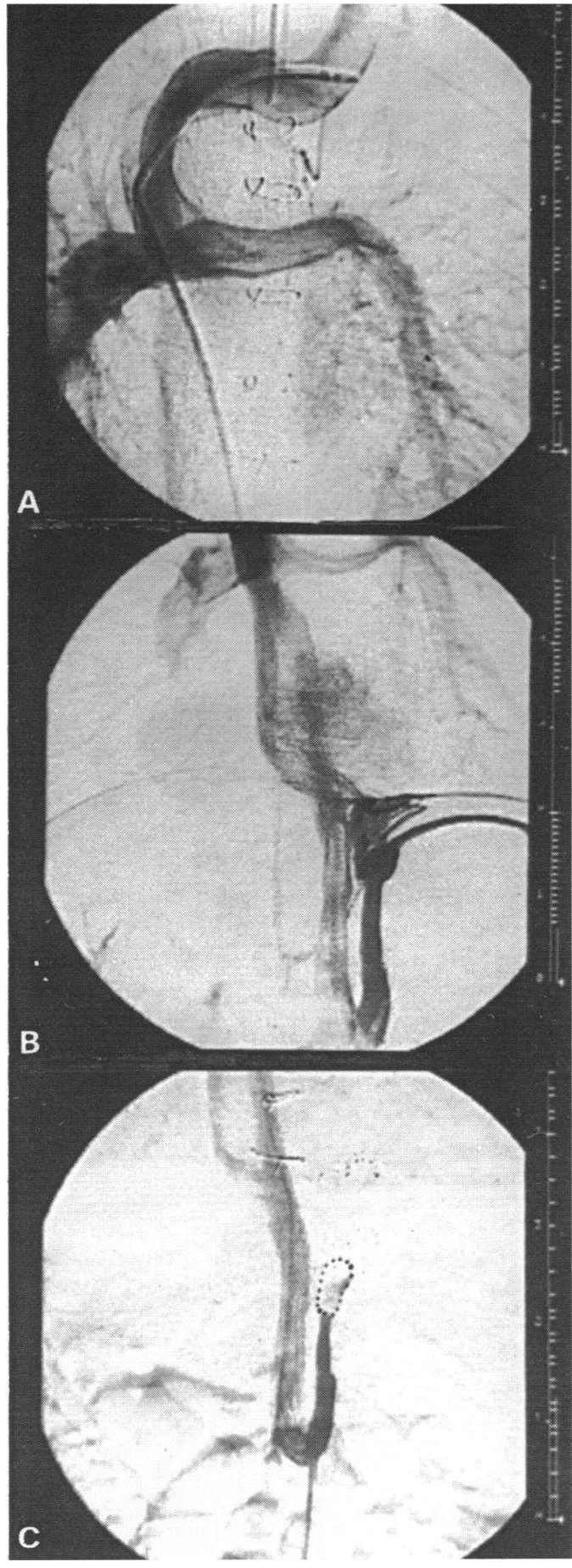

and the hepatic veins via a pericardial vein. This vessel was successfully occluded using three stainless steel coils. Saturations at discharge measured $79 \%$ as opposed to $73 \%$ at rest before the procedure. Anomalous venous collaterals or fistulae were not seen on angiograms of patient no 5 .

\section{Discussion}

The creation of a total cavopulmonary shunt offers very good interim palliation in patients with azygos continuation of the inferior caval vein and complex congenital heart disease. ${ }^{12}$ The remaining right to left shunt which is caused by drainage of hepatic venous blood to the atrial chambers is normally well tolerated. Thus, the creation of a complex intracardiac baffle to redirect hepatic venous blood to the pulmonary arteries is not indicated in these patients. ${ }^{3}$ Moreover, the lower level of hepatic venous pressure after this operation compared with that of a modified Fontan procedure may be beneficial in preserving long-term liver function. Although many patients have undergone total cavopulmonary shunt procedures, there are as yet no reports on longer term follow up.

Systemic venous pressure exceeds portal and hepatic venous pressure after this operation. The pressure difference is dependent on the transpulmonary capillary gradient, which is normally in the magnitude of about $5 \mathrm{~mm} \mathrm{Hg}$. Thus, there would seem to be a risk for the development of fistulae and collateral vessels from the systemic venous to the portal or hepatic venous system. Interestingly, Furuse and colleagues ${ }^{4}$ described one patient who underwent a total cavopulmonary shunt operation and subsequently developed retrograde gastric varices seven years after the operation.

In all patients of this series there was a significant decrease in transcutaneous oxygen saturations at last follow up compared with those of the immediate postoperative period. Exercise testing led to further desaturation in five of the six patients. In one patient there was an increase in saturations during exercise and recovery. This was judged to reveal a ventilation to perfusion mismatch at rest. ${ }^{5} \mathrm{We}$ have not attempted lung perfusion scintigraphy in this or any other patient of this series, because we feel that the technique is inconclusive in the detection of perfusion defects in patients with multiple venous sources of pulmonary blood supply. Cardiac catheterisation in the five patients with further desaturation during exercise testing documented systemic venous to hepatic venous collaterals or fistulae in four patients. Patients with a decrease in oxygen saturations of more than $5 \%$ at peak exercise compared with resting values had such communications. In three patients these collaterals were found to be located below the diaphragm. This finding emphasises the need for detailed angiographic assessment of the infradiaphragmatic veins in the exclusion of systemic to hepatic venous collaterals or fistulae. The vessels were successfully occluded in three patients with a mean rise in resting oxygen saturations of $7 \%$ and profound symptomatic relief.

No patient in this series had pulmonary arteriovenous fistula. This is a recognised complication after creation of Glenn shunts, ${ }^{67}$ however, it has as yet rarely been observed after bidirectional cavopulmonary shunts or modified Fontan procedures. Moore and colleagues ${ }^{8}$ reported two patients with left atrial isomerism and azygos continuation of the inferior vena cava who developed pulmonary arteriovenous fistulae after a modified Fontan procedure in one and a total cavopulmonary shunt in the other. Radionuclide studies for the exclusion of pulmonary arteriovenous 
fistulae ${ }^{5}$ were not carried out in our patient population. The specificity of such studies in patients with systemic venous to hepatic venous fistulae appears to be questionable. We elected to perform selective angiography to document the exact site of any existing fistulae or communications.

\section{Conclusion}

The development of systemic to hepatic venous collaterals is a common finding after total cavopulmonary shunt procedures and can lead to significant cyanosis. Follow up investigations in patients presenting with increasing cyanosis should include exercise stress testing and, if positive, detailed angiographic evaluation of the infra- and supradiaphragmatic systemic veins. Transcatheter balloon or coil embolisation seems to be the technique of choice in the treatment of these lesions.
1 Kreitmann P, Bourlon F, Jourdan J, Dor V. Surgical treatment of primitive ventricle and complex congenital heart malformation with total exclusion of the right heart: report of a case. $\mathcal{F}$ Thorac Cardiovasc Surg 1982;84:150.

2 Kawashima Y, Kitamura S, Matsuda H, Shimazaki Y, Nakano S, Hirose H. Total cavopulmonary shunt operation in complex cardiac anomalies. $\mathcal{F}$ Thorac Cardiovasc Surg 1984;87:74-81.

3 Michielon G, Gharagozloo F, Julsrud P, Danielson GK, Puga FJ. Modified Fontan operation in the presence of anomalies of systemic and pulmonary venous connections. Circulation 1993;88(Pt 2):141-8.

4 Furuse A, Koseni K, Takeshita M, Kotsuka Y, Yagyu K, Kawauchi $M$. Retrograde gastric varices in a patient with total cavopulmonary shunt. Ann Thorac Surg 1993;55: total cavis.

5 Cloutier A, Ash JM, Smallhorn JF, et al. Abnormal distribution of pulmonary blood flow after the Glenn shunt or Fontan procedure: risk of development of arteriovenous fistulae. Circulation 1985;72:471-9.

6 Bargeron LM, Karp RB, Barcia A, Kirklin JW, Hunt D, Deverall PB. Late deterioration of patients after superior vena cava to right pulmonary artery anastomosis. $A m \mathcal{F}$ Cardiol 1972;30:211-6.

7 Kopf GS, Laks H, Stansel HC, Hellenbrand WE, Kleinman CS, Talner NS. Thirty year follow-up of superior vena cava-pulmonary artery (Glenn) shunts. ¥ Thorac Cardiovasc Surg 1990;100:662-71.

8 Moore JW, Kirby WC, Madden WA, Gaither NS Development of pulmonary arteriovenous malformations after modified Fontan operations. $\mathcal{f}$ Thorac Cardiovasc Surg 1989;98:1045-50. 